\title{
Synthesis of Derivatives of 7-(2-Methoxyphenyl)-5-methyl-7H- $[1,3,4]$ thiadiazolo[3,2-a][1,3,5]triazine by Using Benzene Sulphonamide Dibromide as Catalyst
}

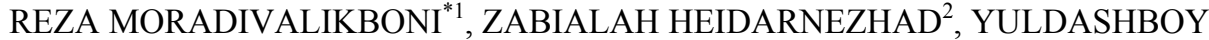 \\ HOZHIBOEV $^{1}$, RAHMAN RAHMANOV ${ }^{1}$ and OYGUL RAHMATULOEVA ${ }^{1}$
}

${ }^{1}$ V.I.Nikitin Institute of Chemistry, Academy of Sciences of the Republic of Tajikistan

${ }^{2}$ Young Researchers Club, Andimeshk Branch, Islamic Azad University, Andimeshk, Iran rmoradi02@yahoo.com

Received 23 November 2013 / Accepted 2 January 2014

\begin{abstract}
One-pot multicomponent condensation of 2-amino 5-H[1,3,4]thiadiazol, aromatic aldehydes, acetamide in the presence benzene sulphonamide dibromide and toluene as solvent was carried out to afford 7-(2-methoxyphenyl)-5-methyl-7H-[1,3,4]thiadiazolo[3,2-a][1,3,5]triazine.
\end{abstract}

Keywords: Multicomponent reaction, Benzene sulphonamide dibromide, Triazine derivatives

\section{Introduction}

Condensed derivatives of 1,3,4-thiadiazole were reported to possess a broad spectrum of biological activity ${ }^{1-4}$, including antibacterial, antitumor, fungicidal and herbicidal properties. However, thiadiazoles and their condensed analogs are still insufficiently studied. In continuation to the search for substances possessing increased ability to permeate through biological membranes of various infectious species ${ }^{5-7}$, we have made attempt to prepare thiadiazolotriazine derivatives.

The diverse and interesting biological activity of thiadiazoles has been reported ${ }^{8-11 .}$ It is well known that these heterocycles are valuable building blocks. Many methods for preparation of these heterocyclic ring systems and their fused analogues have been described in the literature ${ }^{12,13}$. Heterocycles represent the class of compounds that contains the majority of biologically or harmacologically active substances. A vast number of 1,2,4-triazines ${ }^{14,15}$ with antifungal, herbicidal, antibacterial, and tubercolo-static activities have been described.

At first we synthesized benzene sulphonamide dibromide (Figure 1) and then we synthesized thiadiazolotriazine derivatives using benzene sulphonamide dibromide as a catalyst (Figure 2). 


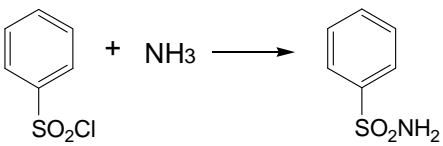

(1)

(3)<smiles>NS(=O)(=O)c1ccccc1</smiles>

(3)<smiles>[18O]=[Fe+]Br</smiles>

(4)<smiles>I[I-]</smiles>

(5)<smiles>CCCCOS(=O)(=O)c1ccccc1</smiles>

(6)

Figure 1. Synthesis of catalyst benzene sulphonamide dibromide (Compound-6)

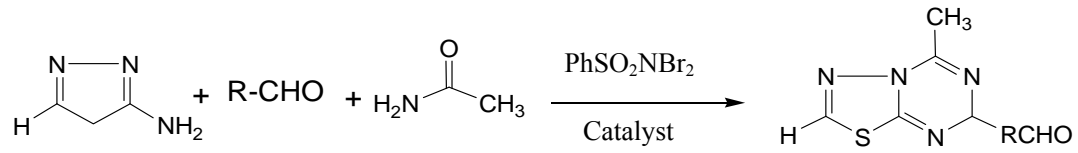

(a)

(b)

(c)

(d-m)

Figure 2. Synthesis of thiadiazolotriazine derivatives using benzene sulphonamide dibromide as a catalyst

\section{Experimental}

A mixture of 2-amino $5 H[1,3,4]$ thiadiazol $(1 \mathrm{mmol})$, benzaldehyde derivatives $(1 \mathrm{mmol})$ and benzene sulphonamide dibromide catalyst $(4 \mathrm{~mol} \%)$ was stirred magnetically at $110{ }^{\circ} \mathrm{C}$ and the progress of the reaction was monitored by thin layer chromatography (TLC). The reaction mixture was filtered.

\section{7-(2-Methoxyphenyl)-5methyl-7H-[1,3,4]thiadiazolo[3,2-a][1,3,5]triazine}

${ }^{1} \mathrm{H}$ NMR $\left(400 \mathrm{MHz}, \mathrm{CDCl}_{3}, \delta \mathrm{ppm}\right): 6.65-6.95(\mathrm{~m}, 5 \mathrm{H}, \mathrm{Ph}), 3.75(\mathrm{~s}, 3 \mathrm{H}, \mathrm{CH} 3), 2.8(\mathrm{~s}, 1 \mathrm{H}, \mathrm{CH})$ $0.9(\mathrm{~s}, 3 \mathrm{H}, \mathrm{CH} 3), 7.50(\mathrm{~s}, \mathrm{H}, \mathrm{H}) .{ }^{13} \mathrm{C}$ NMR $\left(100 \mathrm{MHz}, \mathrm{CDCl}_{3}, \delta \mathrm{ppm}\right): 20.7\left(\mathrm{CH}_{3}\right), 56.2\left(\mathrm{CH}_{3}\right)$, 62.2(CH), 114(CH), 121(CH)), 123.3(C),126.8(CH),130.81(CH), 140.4(CH), 163(C), 164(C).

\section{Results and Discussion}

We synthesized thiadiazolotriazine from thiadiazol and benzaldehyde and acetamide using different amounts of benzene sulphonamide dibromide as catalyst. The reaction performed in the presence of $4 \mathrm{~mol} \%$ catalyst in toluene at $110{ }^{\circ} \mathrm{C}$. The yield of product obtained for different amount of catalyst is listed in Table 1 . It shows that the catalyst concentration increase the yield of product increases. So the reaction may not take place in the absence of catalyst.

Table 1. Effect of amounts of catalyst on the synthesis of benzene sulphonamide dibromide ${ }^{\mathrm{a}}$

\begin{tabular}{clc}
\hline Entry & Mol \% Catalyst & $\%$, Yield $^{\mathrm{b}}$ \\
\hline 1 & 0.5 & 40 \\
2 & 1 & 60 \\
3 & 2 & 80 \\
4 & 4 & 90 \\
\hline
\end{tabular}

${ }^{a}$ Reactions were carried out with thiadiazolotriazine, benzaldehyde and acetamide using benzene sulphonamide dibromide as catalyst at equimolar ratio(1:1); ${ }^{b}$ Yields refer to isolated pure products.

To show the generality and applicability of this procedure, we treated thiadiazol and acetamide and a wide variety of benzaldehydes in the presence of a catalytic amount of benzene sulphonamide dibromide at $110{ }^{\circ} \mathrm{C}$ and obtained the desirable products in good to excellent yields (Table 2). On the basis of the results obtained so far, it seems that the functional groups of the aromatic ring affect the reactivity. As shown in Table 2, the reaction of thiadiazol, acetamide and benzaldehyde derivatives having an electron-donating 
group immediately gave the desired products in excellent yields (entries 4) and those having an electron-withdrawing group were performed the reaction for long time in excellent yields (entries 2 and 3,5).

Table 2. Synthesis of thiadiazolotriazine from various thiadizole and aldehydes<smiles>COc1ccc([N+](=O)[O-])cc1-c1nc2c(nc(C3N=C4SC(C)=NN4C(C)=NC3c3ccccc3OC)c3nc(C4N=C(C)N5C(C)=NC(c6cc([N+](=O)[O-])ccc6OC)N=C5S4)nn32)s1</smiles>

${ }^{a}$ Reactions were carried out with thiadiazol and benzaldehyde using benzene sulphonamide dibromide as a catalyst at equimolar ratio(1:1). ${ }^{b}$ Yields refer to isolated pure products 


\section{Conclusion}

The toluene has been employed as highly efficient solvent system for the convenient preparation of thiadiazolotriazine derivatives in excellent yields from thiadiazol and acetamide and a wide variety of benzaldehydes using benzene sulphonamide dibromide as catalyst. In addition to low cost, availability of catalyst we describe a method in which benzene sulphonamide dibromide is a highly efficient catalyst for the synthesis of thiadiazolotriazine derivatives. The advantages include low cost, ease of catalyst handling, mild reaction conditions and reactions carried out with excellent yields.

\section{Acknowledgement}

The authors are thankful to the Mazandran University Research Council for the partial support for this research and thankful to Dr Heshmatollah Alinezhad .

\section{References}

1. Japan Patent Application No. 63-10794 (1987); Ref Zh Khim., 1989, 110402P.

2. US Patent No. 4742063 (1987); Ref. Zh. Khim., 1989, 10401P.

3. US Patent No. 4866064 (1989); Ref. Zh. Khim., 1991, 70384P.

4. Suiko I, Hayashida S and Nakatsu S, Agric Biol Chem., 1982, 46(11), 2691-2695.

5. Sattorov S S, Kukaniev M A,, Sanginov Z G et al., Proc Rep Conf "Advances in Chemistry and Chemical Technology” [in Russian], Dushanbe, 2002, 142-144.

6. Coburn R A, Glennon R A and Chmielewicz Z F, J Med Chem., 1974, 17(9), 1025 1027; DOI: $10.1021 / \mathrm{jm} 00255 \mathrm{a} 029$

7. Russo F, Santagati A, Santagati M et al., Farmaco Ed Sc., 1987, 42(6), 437-447.

8. Carraro F, Pucci A, Naldini A, Schenone S, Bruno O and Ranise A et al., J Med Chem., 2004, 47, 1595-1598; DOI: 10.1021/jm034257u

9. Mylari B L, Oates P J, Zembrowski W J, Beebe D A, Conn E L and Coutcher J B, et al., J Med Chem., 2002, 45, 4398-401; DOI: 10.1021/jm020288y

10. Prekupec S, Makuc D, Plavec J, Suman L, Kralj M, Pavelic K et al., J Med Chem., 2007, 50, 3037-3045; DOI:10.1021/jm0614329

11. Gazivoda T, Sokcevic M, Kralj M, Suman L, Pavelic K, De Clercq E et al., J Med Chem., 2007, 50, 4105-4112; DOI: 10.1021/jm070324z

12. Singh H, Yadav L D S, Shukla K N and Diwedi R, J Agric Food Chem 1990, 38, 1962-1964.

13. Kornis G, Marks P J and Chidester C G, J Org Chem., 1980, 45, 4860-4863.

14. Neunhoeffer H, In Comprehensive Heterocyclic Chemistry; Katritzky A R and Rees C W, Eds., Pergamon Press, Oxford, 1984, 3(2B), 385.

15. Neunhoeffer H: In Comprehensive Heterocyclic Chemistry II; Katritzky A R, Rees C W and Scriven E F V Eds., Pergamon Press: Oxford, 1996, 507(6); (a) Katritzky A R, Ramsden C, Scriven E F V and Taylor R Eds., In Comprehensive Heterocyclic Chemistry III, Elsevier, Amsterdam, 2008, 9. 